\title{
Resenha do livro em língua inglesa Manual das religiões contemporâneas do Brasil, 2016, editado por Bettina E. Schmidt e Steven Engler
}

\author{
Reseña del libro inglés Manual de las religiones contem- \\ poráneas de Brasil, 2016, editado por Bettina E. Schmidt y \\ Steven Engler
}

Book review of the Handbook of Contemporary Religions in Brazil, 2016, edited by Bettina E. Schmidt y Steven Engler

\section{Resumo}

\section{Helmut Renders*}

Resenha do livro SCHMIDT, Bettina E.; ENGLER, Steven (Orgs.). Handbook of Contemporary Religions in Brazil. Leiden, Brill, 2016 (Coletânea: Brill Handbooks on Contemporary Religion, vol. 13). ISBN 978-90-04-32185-4 (capa dura), ISBN 978-9004-32213-4 (e-book).

\section{Resumen}

Reseña del libro SCHMIDT, Bettina E.; ENGLER, Steven (eds.). Handbook of Contemporary Religions in Brazil. Leiden, Brill, 2016 (Coletânea: Brill Handbooks on Contemporary Religion, vol. 13). ISBN 978-90-04-32185-4 (impresso), ISBN 978-90-04-32213-4 (e-book).

\section{Abstract}

Book review of SCHMIDT, Bettina E.; ENGLER, Steven (eds.). Handbook of Contemporary Religions in Brazil. Leiden, Brill, 2016 (Coletânea: Brill Handbooks on Contemporary Religion, vol. 13). ISBN 978-90-04-32185-4 (hardback), ISBN 978-90-04-32213-4 (e-book).

\footnotetext{
Doutor em Ciências da Religião - UMESP com pós-doutorado em Ciência da Religião - Universidade Federal de Juiz de Fora [UFJF]. É professor associado da Universidade Metodista de São Paulo no Programa de Pós-graduação em Ciências da Religião e da Faculdade de Teologia.
} 


\section{Introdução}

Este manual de 30 artigos conta com a participação de 19 professores/ as atuando em universidades brasileiras das regiões sul, sudeste e centro-oeste, sete em programas de Ciências da religião (PUC-SP [quatro professores e um colaborador], UMESP, Mackenzie) e 12 em universidades públicas em programas afins como a história e antropologia (UFMG, UFGD, USP [seis professores/as], UNIFESP, UFSC, UFRS [dois professores/as]). Além disso, conta o texto com as contribuições de 10 pesquisadoras, o que representa um terço de todos/as professores/as, e que vai muito além da presença da pesquisadora mulher nos corpos docentes dos PPGs em ciência da religião (e teologia) no Brasil.

Em sua introdução, afirmam Steven Engler, professor de Religious Studies na Mount Royal University in Calgary e na Concordia University in Montreal, e professor colaborador no PPG em Ciência da Religião da PUC-SP, e a antropóloga cultural Bettina E. Schmidt, professora de Study of Religions na University of Wales Trinity Saint David, com passagens pela Oxford University, na Inglaterra, e a Philipps-University Marburg, na Alemanha, como objetivo principal deste manual:

Duas áreas da geografia religiosa brasileira receberam atenção desproporcional: estudos antropológicos de selecionadas tradições afro-brasileiras e estudos sociológicos de grupos evangélicos e / ou pentecostais. Este manual, embora não negligencie estes tópicos e estas abordagens, oferece um retrato mais completo, equilibrado e contextualizado das religiões contemporâneas no Brasil (p. 1).

Verifica-se que, quanto à questão da maior abrangência, o objetivo foi atendido. $\mathrm{O}$ manual certamente representa o estudo atual mais completo do campo religião do Brasil em língua estrangeira.

\section{Organização do livro}

A obra é organizada em três partes. A primeira, dedicada à descrição de religiões distintas, com 17 capítulos, é a maior; a segunda, com quatro capítulos, é a menor; a terceira é composta por nove capítulos. O primeiro capítulo poderia ter sido ainda maior, considerando que o protestantismo tradicional e o pentecostalismo foram apresentados cada um em um só artigo. O catolicismo, além de falar do seu movimento carismático e da sua vertente popular, ficou completamente de fora. O judaísmo somente aparece em uma 
das suas vertentes de avivamento. Além do Vale do Amanhecer, há um número considerável de novas religiões, com um dos seus centros únicos no mundo, localizado na Grande-Brasília/Goiás. Nesse primeiro capítulo há dois artigos a respeito de religiões indígenas e dois artigos sobre religiões afro. $\mathrm{Na}$ segunda parte, poderia também falar do catolicismo brasileiro na diáspora. A terceira parte foca a questão de gênero nas mulheres nas religiões afro, mas não se aborda o conflito entre evangélicos, pentecostais, neopentecostais e os católicos (chutar a santa, por exemplo). Os capítulos variam em tamanho, entre menos de dez páginas até mais de trinta páginas, algo compreensível pelos assuntos tratados, mas algumas vezes não. Mas, com certeza, o manual consegue colocar as religiões do Brasil no mapa dos estudos da religião em nível mundial, como décimo terceiro volume acerca de religiões contemporâneas.

Em detalhe, a obra se apresenta da seguinte forma:

\section{Introdução 1 / Steven Engler e Bettina E. Schmidt}

\section{Parte 1: Religiões no Brasil}

1. Traços comuns das religiões indígenas brasileiras / Mark Münzel - 33

2. Religião de grupos de fala Guarani no Brasil / Graciela Chamorro - 47

3. Catolicismo popular tradicional no Brasil / Carlos Alberto Steil - 60

4. O espírito do Brasil: cristandade carismática nas maiores populações católicas e pentecostais do mundo / R. Andrew Chesnut - 76

5. Protestantismo tradicional / Leonildo Silveira Campos - 95

6. Pentecostalismo no Brasil / Paulo Barrera Rivera - 117

7. Mórmons no Brasil / David Clark Knowlton - 132

8. Religiões sob influência afro-brasileira e indígena / Steven Engler e Énio Brito - 142

9. Candomblé: Religião, visão do mundo e experiência / Vagner Gonçalves da Silva e Fernando Giobellina Brumana - 170

10. Kardecismo / Steven Engler e Artur Cesar Isaia - 186

11. Umbanda / Steven Engler - 204

12. Se tornar um Jaguar: Trilhas espirituais no Vale do Amanhecer / Emily Pierini - 225

13. As religiões ayahuasca do Brasil: Comparação e contrastes / Andrew Dawson - 233

14. Avivamentos judaicos no Brasil / Marta F. Topel - 253

15. Islã na geografia religiosa brasileira / Cristina Maria de Castro - 267 
16. Budismo, Shinto, novas religiões japonesas no Brasil / Frank Usarski e Rafael Shoji - 279

17. Novas religiões hindus no Brasil: O movimento Hare Krishna / Silas Guerriero - 295

Parte 2 Religiões brasileiras na diáspora

18. Evangélicos e neopentecostais brasileiros na diáspora / Daniel Clark - 305

19. Orixás além do Atlântico: a diáspora de religiões afro-brasileiras na Europa / Clara Saraiva - 320

20. Santo Daime na diáspora / Gillian Watt - 333

21. A globalização do Movimento João de Deus: tradição cultural como globalização / Cristina Rocha - 346

Parte 3 Assuntos especiais das religiões brasileiras

22. Religião e política no Brasil / Ricardo Mariano e Ari Pedro Oro - 363 23. Secularismo e a religião na esfera pública no Brasil contemporâneo / Paula Montero - 379

24. Mulheres e religião no Brasil contemporâneo / Kelly E. Hayes - 395 25. Possessão por espíritos / Bettina E. Schmidt - 431

26. Negritude, desigualdades e religião: o caso do Candomblé / Andreas Hofbauer - 448

27. A reafricanização nas religiões afro-brasileiras: repensando o sincretismo religioso / Stefania Capone -473

28. Na encruzilhada: conflitos entre o neopentecostalíssimo e as religiões afro-brasileiras / Vagner Gonçalves da Silva - 489

29. Evangelismo afro e música no Brasil / John Burdick - 508

30. Objetos e imagens nas religiões brasileiras / Roger Sansi - 515 Sumário - 535

\section{Observações e recomendações}

Há uma diversidade no uso do conceito da religião. Em geral, usa-se o plural, mas às vezes, como nos capítulos 2, 9, [15], 22, 23 e 24, usa-se o singular. Não se parte no manual de uma definição de trabalho, mas alerta-se na introdução que “... religiões e 'religião' deveriam ser estudadas no seu contexto [...] e que as linhas entre religião e outras expressões de empreendimentos humanos, em grande parte, são construídas pelos passos concretos 
das próprias atividades acadêmicas" (p. 19). Depois, transparece o tema pontualmente, quando se necessita qualificar ou problematizar o seu uso. ${ }^{1}$

Não há nesta resenha lugar suficiente para dialogar com todos os textos, os seus autores e as suas autoras, embora mereçam, visto que a qualidade e a densidade desses textos são altas. Observamos que há textos que representam mais a consolidação do estado da pesquisa (Campos e Rivera, por exemplo), enquanto outros articulam perspectivas e preocupações mais recentes (Sansi; os estudos da cultura material e visual são novos, mesmo que ele ainda não contemple a cultura visual protestante ou católica). Novidade para a pesquisa fora do Brasil devem ser os estudos inter-religiosos ou comparativos, tanto em relação à criação de novos movimentos religiosos, quanto em relação aos conflitos inter-religiosos, e a discussão de itens inerentes ao campo religioso brasileiro. Além disso, há também movimentos urbanos do neoxamanismo. Mas tudo isso não desfaz os avanços que este título representa. Ele introduz muitas facetas do campo religioso brasileiro, relaciona perspectivas de dentro e de fora, e evidencia que o campo religioso brasileiro continua sendo altamente rico, dinâmico e, além disso, relevante para o estudo da sociedade brasileira como um todo.

O livro não é barato, ele custa 185 euros, o que representa hoje ao redor de 660 reais. Entretanto, trata-se de um texto que ficará por um bom tempo sem similar, e que deveria estar em toda biblioteca universitária, como também nas bibliotecas dos seminários teológicos, protestantes, pentecostais e neopentecostais e de outras religiões. Brill Leiden está de parabéns por publicar este manual.

1 O tema não está plenamente ausente. O artigo sobre o islã discute compreensões exclusivistas e inclusivistas dentro do próprio islã brasileiro (cf. p. 273); no texto a respeito do Santo Daime, interessa a definição legal da religião, questão vinculada ao seu registro público (p. 373) e, finalmente, aparece o tema da "classificação" como religião em relação aos grupos ayahuasca e ao Vale do Amanhecer (p. 417). 